\title{
Brain Temperature Measured by Magnetic Resonance Spectroscopy to Predict Clinical Outcome in Patients with Infarction
}

\author{
Tomohisa Ishida ${ }^{1}$, Takashi Inoue ${ }^{1, *(\mathbb{D})}$, Tomoo Inoue ${ }^{1}$, Toshiki Endo $^{2}$, Miki Fujimura ${ }^{2}$, Kuniyasu Niizuma ${ }^{3} \mathbb{D}$, \\ Hidenori Endo ${ }^{3}$ and Teiji Tominaga ${ }^{3}$
}

1 Department of Neurosurgery, National Hospital Organization Sendai Medical Center, 2-11-12 Miyagino, Sendai, Miyagi 983-8520, Japan; tomy.ixxx4@gmail.com (T.I.); tomoo49@gmail.com (T.I.)

2 Department of Neurosurgery, Kohnan Hospital, 4-20-1 Nagamachiminami, Sendai, Miyagi 982-0012, Japan; endo@nsg.med.tohoku.ac.jp (T.E.); fujimur@nsg.med.tohoku.ac.jp (M.F.)

3 Department of Neurosurgery, Tohoku University Graduate School of Medicine, 2-1 Seiryomachi, Sendai, Miyagi 980-8575, Japan; niizuma@nsg.med.tohoku.ac.jp (K.N.); hideendo@gmail.com (H.E.); tomi@nsg.med.tohoku.ac.jp (T.T.)

* Correspondence: tainoue-nsu@umin.ac.jp; Tel.: +81-22-293-1111

Citation: Ishida, T.; Inoue, T.; Inoue, T.; Endo, T.; Fujimura, M.; Niizuma, K.; Endo, H.; Tominaga, T. Brain Temperature Measured by Magnetic Resonance Spectroscopy to Predict Clinical Outcome in Patients with Infarction. Sensors 2021, 21, 490. https://doi.org/10.3390/s21020490

Received: 28 December 2020

Accepted: 7 January 2021

Published: 12 January 2021

Publisher's Note: MDPI stays neutral with regard to jurisdictional clai$\mathrm{ms}$ in published maps and institutional affiliations.

Copyright: $\odot 2021$ by the authors. Licensee MDPI, Basel, Switzerland. This article is an open access article distributed under the terms and conditions of the Creative Commons Attribution (CC BY) license (https:// creativecommons.org/licenses/by/ $4.0 /)$.

\begin{abstract}
Acute ischemic stroke is characterized by dynamic changes in metabolism and hemodynamics, which can affect brain temperature. We used proton magnetic resonance (MR) spectroscopy under everyday clinical settings to measure brain temperature in seven patients with internal carotid artery occlusion to explore the relationship between lesion temperature and clinical course. Regions of interest were selected in the infarct area and the corresponding contralateral region. Single-voxel MR spectroscopy was performed using the following parameters: 2000-ms repetition time, 144-ms echo time, and 128 excitations. Brain temperature was calculated from the chemical shift between water and $\mathrm{N}$-acetyl aspartate, choline-containing compounds, or creatine phosphate. Within $48 \mathrm{~h}$ of onset, compared with the contralateral region temperature, brain temperature in the ischemic lesion was lower in five patients and higher in two patients. Severe brain swelling occurred subsequently in three of the five patients with lower lesion temperatures, but in neither of the two patients with higher lesion temperatures. The use of proton MR spectroscopy to measure brain temperature in patients with internal carotid artery occlusion may predict brain swelling and subsequent motor deficits, allowing for more effective early surgical intervention. Moreover, our methodology allows for MR spectroscopy to be used in everyday clinical settings.
\end{abstract}

Keywords: acute ischemic stroke; brain temperature; magnetic resonance spectroscopy; less invasive; clinical outcomes; cerebral blood flow change

\section{Introduction}

Brain thermoregulation depends on a delicate balance between heat-producing and heat-dissipating mechanisms [1-3]. Fundamentally, brain temperature in the healthy human at rest is determined by the balance between heat produced by cerebral energy turnover, which is identical to cerebral metabolism, and heat that is removed, primarily by cerebral blood flow [4-6]. The disturbance of this homeostasis following central nervous system injury, such as cerebrovascular ischemia, may cause progressive ischemic damage to neuronal substrates because of higher brain temperatures [7,8]; this may lead to more severe motor deficits, among other impairments. For example, higher brain temperatures in the affected regions of patients with unilateral internal carotid stenosis have been reported to predict hyperperfusion after carotid endarterectomy, with related motor weakness [9]. Therefore, monitoring and therapeutic modulation of brain temperature after acute ischemic stroke are important for assessing clinical conditions and treatment options, to avoid severe motor dysfunction and death. 
Brain swelling associated with large ischemic areas can cause severe motor deficits and may be life threatening [10]. Early predictors of brain swelling are urgently needed because decompressive surgery before the occurrence of clinical deterioration can lead to better outcomes [11,12]; however, to date, no such early predictors have been established [6]. Although early elevations in brain temperature are known to indicate poor neurological outcomes $[13,14]$, the relationship between brain temperature and brain swelling remains unclear and requires further investigation.

In human patients, noninvasive methods for monitoring brain temperature in clinical situations are needed [15]. Proton magnetic resonance (MR) spectroscopy has been demonstrated to accurately measure brain temperature in both animals [16-18] and humans $[9,13,14,16,19-21]$. In this technique, chemical shifts of water protons are measured against an abundant internal reference, such as $N$-acetyl aspartate (NAA) [22], choline, and/or creatine [23-25], allowing for relatively accurate measurements of brain temperature [15]. However, for various reasons, MR spectroscopy is not commonly used to measure brain temperature in everyday clinical practice. For example, although a recent study reported that calibration measurements are important for accurate brain temperature estimation when using this approach [26], their application is impractical in single patients. Thus, to assess the clinical value of this technique, methods that can enable its use under everyday conditions are needed.

In the present study, we aimed to investigate the use of proton MR spectroscopy to noninvasively measure brain temperatures in patients with severe ischemic stroke using a relatively simple method that is appropriate for everyday clinical use. Our preliminary findings suggest that this technology might be useful for predicting clinical courses, including motor function, in such patients. In the future, this technique could be used to indicate severe brain swelling before it occurs, thus allowing for earlier treatment and better patient prognosis.

\section{Subjects and Methods}

\subsection{Patient Characteristics}

This study included patients with internal carotid artery occlusion who were admitted to our hospital within $24 \mathrm{~h}$ from the onset and could have undergone MR spectroscopy within $48 \mathrm{~h}$. One female and six male patients (aged 57-88 years) with internal carotid artery occlusion in the acute stage and National Institutes of Health Stroke Scale scores of 18 to 37 (median 25.7) were enrolled. The modified Rankin Scale was used to measure the degree of disability in each patient at discharge, or within 5 days after admission in the patients who died before discharge. MR imaging was obtained at 15 to $48 \mathrm{~h}$ (median $24 \mathrm{~h}$ ) after onset. The time of onset was taken as the first occurrence of symptoms; if the patient awoke with stroke, then the time of onset was taken as the time that the patient was last known to be symptom-free. The study protocol was approved by the Ethics Committee of Kohnan Hospital (approval number Rin2010-01) and performed in accordance with the guidelines of the latest version of the Declaration of Helsinki. Written informed consent was given by each patient's family prior to the study.

\subsection{MR Imaging}

All MR imaging was performed using a Signa VH/i 3.0 T MR imaging system (General Electric Medical Systems, Milwaukee, WI, USA) and parallel imaging head coil. Imaging with a $3.0 \mathrm{~T}$ system has been previously reported to give good accuracy $[27,28]$. For T2weighted MR imaging, the short inversion time inversion recovery sequence was used with the following parameters: repetition time (TR), $4000 \mathrm{~ms}$; echo time (TE), $81 \mathrm{~ms}$; inversion time, $100 \mathrm{~ms}$; matrix, $512 \times 384$; field of view, $400 \mathrm{~mm}$; and 3.5-mm slice thickness. Single-voxel MR spectroscopy was performed with the following parameters: TR $2000 \mathrm{~ms}$, TE $144 \mathrm{~ms}$, and 128 excitations. A point-resolved spectroscopy pulse sequence was used. The voxels of interest, with a size of $20 \mathrm{~mm} \times 20 \mathrm{~mm} \times 30 \mathrm{~mm}$, were set in the infarct area and the contralateral area of each patient, as identified on T2-weighted images (Figure 1). 
The image acquisition took $15 \mathrm{~min}$ (not including patient settling time), and the environmental temperature was maintained at $21^{\circ} \mathrm{C}$ to $25^{\circ} \mathrm{C}$. The MR spectra included peaks assigned to choline-containing compounds at 3.2 parts per million (ppm), creatine phosphate at $3.0 \mathrm{ppm}$, and NAA at $2.0 \mathrm{ppm}$. All spectra were inspected visually and discarded if judged to be of poor quality (i.e., if the signal-to-noise ratio was such that peaks were unable to be detected). Brain temperature was calculated from the chemical shift between water and choline-containing compounds, creatine phosphate, or NAA; the most recognizable of the three peaks was used for each measurement. To calculate the brain temperature, a $0.01 \mathrm{ppm}$ shift in the water peak was taken as a $1{ }^{\circ} \mathrm{C}$ change $[6,9,29]$. The ratio of brain temperature in the affected hemisphere to that in the contralateral hemisphere was then calculated for each patient, as reported previously [6,9].

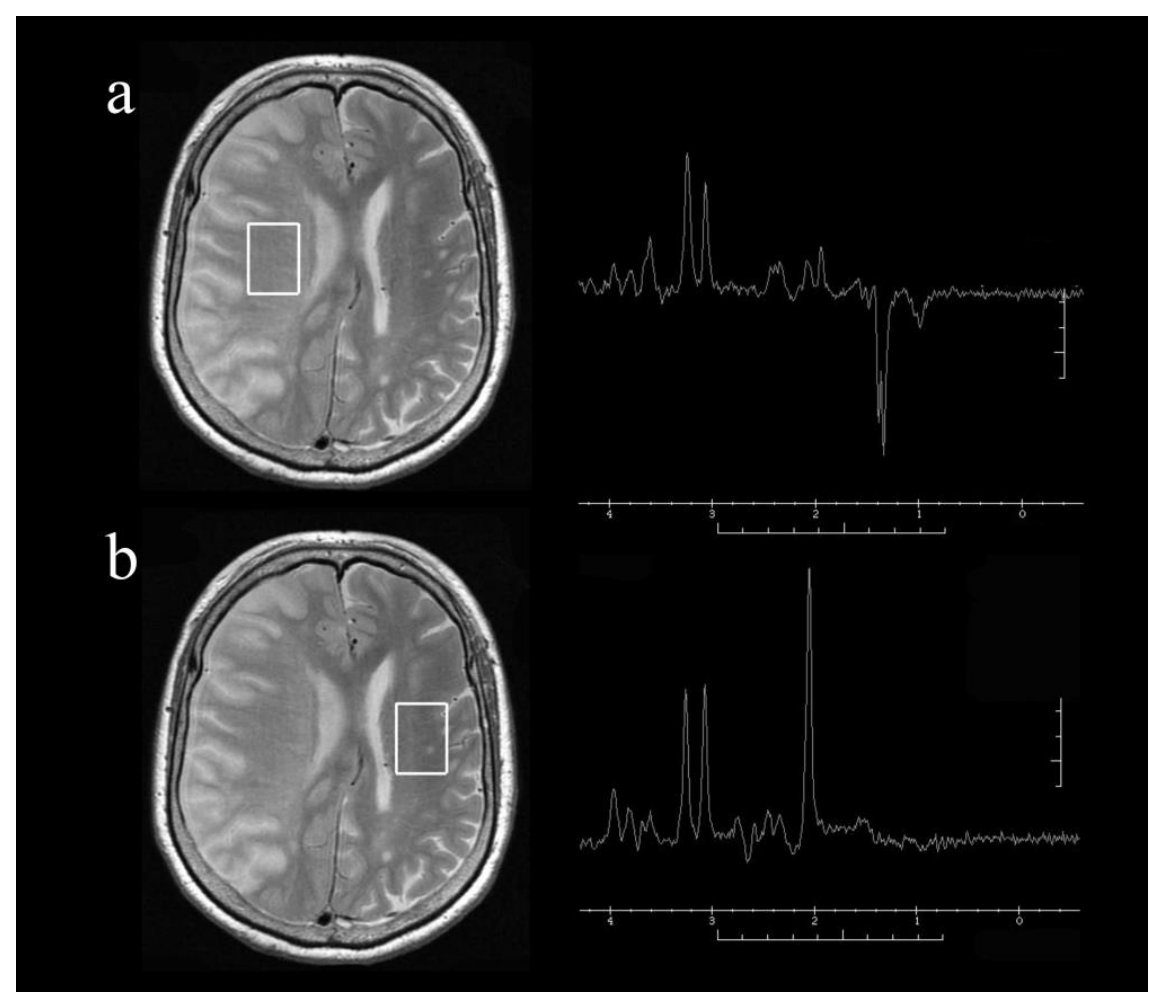

Figure 1. Representative axial T2-weighted magnetic resonance images and single-voxel proton magnetic resonance spectra obtained from the voxels of interest (square areas) in the infarct hemisphere (a) and normal hemisphere (b) of a patient with right internal carotid artery occlusion at $24 \mathrm{~h}$ after onset. Note the presence of lactate with relatively preserved $N$-acetyl aspartate (NAA) in the infarct hemisphere.

\section{Results}

The mean brain temperature, as measured by MR spectroscopy, was $38.7^{\circ} \mathrm{C} \pm 13.7^{\circ} \mathrm{C}$ (mean \pm standard deviation). Mean systemic temperature measured by an electronic clinical thermometer in the armpit was $37.4^{\circ} \mathrm{C} \pm 0.5^{\circ} \mathrm{C}$. Table 1 shows the clinical summaries and brain temperature ratios of the seven patients. Two patients had a higher brain temperature on the pathological side than on the contralateral side (i.e., a ratio above 1), and neither of these patients had subsequent severe brain swelling. The other five patients had a lower brain temperature on the pathological side than on the contralateral side (i.e., a ratio below 1). Three of these five patients died of severe brain swelling with excessive midline shift. The $p$ value was 0.1473 in the Chi-square test. In all patients, brain temperatures were measured before any severe brain swelling or clinical signs of herniation were detected. 
Table 1. Summary of clinical findings in seven patients with internal carotid artery occlusion.

\begin{tabular}{|c|c|c|c|c|c|c|c|c|c|c|}
\hline Case No. & Age (Years) & Sex & Side of Occlusion & $\begin{array}{c}\text { Brain Temperature } \\
\text { Ratio }^{1}\end{array}$ & $\begin{array}{l}\text { Time from } \\
\text { Onset (h) }\end{array}$ & $\begin{array}{c}\text { Severe Brain } \\
\text { Swelling }(-/+)\end{array}$ & mRS & $\begin{array}{l}\text { Systemic } \\
\text { Temp. }\left({ }^{\circ} \mathrm{C}\right)\end{array}$ & NIHSS & $\begin{array}{c}\text { Time to Death/ } \\
\text { Discharge (Days) }\end{array}$ \\
\hline 1 & 72 & Male & $\mathrm{Rt}$ & 1.5 & 31 & - & 5 & 37.8 & 18 & 50 \\
\hline 2 & 57 & Male & Rt & 1.23 & 28 & - & 5 & 37.5 & 29 & 27 \\
\hline 3 & 88 & Male & $\mathrm{Lt}$ & 0.91 & 24 & + & 6 & 37.2 & 37 & 5 \\
\hline 4 & 69 & Male & $\mathrm{Lt}$ & 0.8 & 48 & - & 5 & 37.6 & 27 & 54 \\
\hline 5 & 87 & Female & Rt & 0.78 & 24 & + & 6 & 37.3 & 21 & 4 \\
\hline 7 & 70 & Male & Rt & 0.67 & 15 & - & 5 & 37.1 & 18 & 62 \\
\hline
\end{tabular}

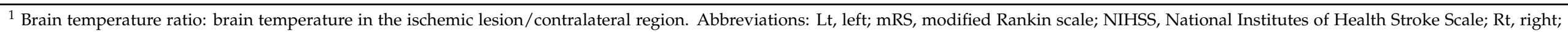
temp., temperature. 


\section{Discussion}

The present study demonstrated that brain temperature can be measured noninvasively in patients in the acute stage of severe ischemic stroke using MR thermometry under everyday clinical conditions. Some patients had higher brain temperatures in the stroke lesion compared with the contralateral region, while other patients had lower brain temperatures in the stroke lesion. Notably, all patients who subsequently suffered herniation had lower brain temperatures in the stroke lesion compared with the contralateral region.

Brain temperature may theoretically be elevated in hypoperfused but viable tissues, such as the ischemic penumbra, if the ischemic tissue is metabolically active but the clearance of heat is insufficient $[7,30,31]$. Brain temperature gradually decreases with the development of more mature areas of infarction in which hypoperfusion has resulted in metabolically inert tissues $[14,19]$. In a previous study, brain temperatures were measured both invasively, using a sensor passed through a burr hole or craniotomy, and noninvasively, using MR spectroscopy. Brain temperature in the infarcted hemisphere was higher than that in the contralateral hemisphere at $6 \mathrm{~h}$ after middle cerebral artery infarction, but gradually became lower than that in the contralateral hemisphere after $12 \mathrm{~h} \mathrm{[16].} \mathrm{In} \mathrm{the} \mathrm{present} \mathrm{study,}$ a noninvasive measurement of the ischemic core lesion also demonstrated predominantly lower temperatures in patients between 15 and $48 \mathrm{~h}$ after infarction.

Interestingly, in the present study, all three patients who subsequently underwent herniation caused by severe brain swelling had a lower brain temperature in the lesion compared with the contralateral region. The lower brain temperature in the lesion was observed before the occurrence of severe brain swelling or any clinical signs of herniation. Similarly, direct monitoring has previously revealed that brain temperatures fall below bladder temperatures some hours before the occurrence of bilateral pupil dilation and fixation, or clinical signs of herniation [19]. This finding may be supported by other biological evidence. For example, brain swelling is caused by both angioedema and cellular edema [10-12]. Such edema might occur with local reperfusion from the collateral vessels, and may cause a decline in brain temperature as a result of the heat clearance effect. Thus, decreases in temperature may occur earlier in the presence of brain edema. The-observation of temperature changes in the acute phase of ischemia may therefore be an early indicator of the risk of brain herniation and may lead to more effective surgical intervention. The present finding of a possible relationship between brain temperature and brain swelling after ischemic stroke may, therefore, have important implications for its treatment and might lead to better motor outcomes in patients.

Although many clinical studies have used MR spectroscopy to measure brain temperatures under strict experimental protocols $[9,13,14,16,19,20]$, the present study focused on the use of this technique in everyday clinical practice, where many factors are unable to be controlled. Specifically, we used a relatively common 3.0 T MR imaging system, with a short imaging time, small voxel size, and simple calculation method for clinical usage. We were also flexible with regard to the time period between infarction and temperature measurement and used a temperature ratio (rather than the more commonly used temperature difference) as a simple control for external factors. Taken together, these techniques will facilitate the use of MR spectroscopy for measuring brain temperature in everyday clinical practice.

Several limitations of this study should be acknowledged. The small sample size is a major limitation, and a larger study is needed to confirm our preliminary findings. Sequential measurements should be made in each patient to investigate changes in brain temperature over time. In addition, in the present study, although the average brain temperature was similar to that reported via direct measurements of neurosurgical patients [32], the measured brain temperatures varied widely, and accurate temperature readings were difficult to confirm, similar to reports in traumatically injured brain tissue [8]. This may be because MR thermometry can be affected by the ambient temperature and other factors, such as $\mathrm{pH}$. Moreover, MR spectra may change during imaging because of dynamic changes in both metabolism and hemodynamics in the acute phase [6]. In an attempt to 
control for these factors, we calculated the ratio of the pathological side of the brain to the contralateral side of the brain to reduce variance. This simple method of controlling for some outside factors means that our technique is better suited to clinical use, where such factors are often unable to be controlled directly.

In conclusion, changes in brain temperature in stroke lesions can be measured using MR spectroscopy under everyday clinical conditions. A lower brain temperature in the lesion compared with the contralateral region may indicate a higher risk of subsequent brain swelling in patients with internal carotid artery occlusion, although further studies are required. Accurately predicting future brain swelling is important because it will allow for more effective early surgical intervention, thereby potentially lowering both mortality and the severity of motor deficits in patients.

Author Contributions: Conceptualization, T.I. (Takashi Inoue); methodology, T.I. (Takashi Inoue) and K.N.; software, T.I. (Tomohisa Ishida); validation, T.I. (Tomoo Inoue), T.E., M.F., H.E., and T.T.; formal analysis, T.I. (Tomohisa Ishida), T.I. (Takashi Inoue), and T.I. (Tomoo Inoue); investigation, T.I. (Tomohisa Ishida), T.I. (Takashi Inoue), T.I. (Tomoo Inoue), and K.N.; resources, T.I. (Tomoo Inoue), M.F., and T.T.; data curation, T.I. (Tomohisa Ishida), T.E., and H.E.; writing-original draft preparation, T.I. (Tomohisa Ishida) and T.I. (Takashi Inoue); writing-review and editing, T.I. (Takashi Inoue), T.I. (Tomoo Inoue), T.E., M.F., K.N., H.E., and T.T.; visualization, T.I. (Tomohisa Ishida) and K.N.; supervision, T.I. (Takashi Inoue) and T.T.; project administration, T.I. (Takashi Inoue); funding acquisition, K.N. and T.T. All authors have read and agreed to the published version of the manuscript.

Funding: This research received no external funding.

Institutional Review Board Statement: The study was conducted according to the guidelines of the Declaration of Helsinki, and approved by the Ethics Committee of Kohnan Hospital (protocol code: Rin2010-01, date of approval: January 2010).

Informed Consent Statement: Informed consent was obtained from all subjects' families involved in the study.

Data Availability Statement: The data presented in this study are available on request from the corresponding author. The data are not publicly available for reasons of privacy.

Acknowledgments: We thank Bronwen Gardner, from Edanz Group (https: / / en-author-services. edanz.com/ac) for editing a draft of this manuscript.

Conflicts of Interest: The authors declare no conflict of interest.

\section{References}

1. Busto, R.; Dietrich, W.D.; Globus, M.Y.; Valdes, I.; Scheinberg, P.; Ginsberg, M.D. Small differences in intraischemic brain temperature critically determine the extent of ischemic neuronal injury. J. Cereb. Blood Flow Metab. 1987, 7, 729-738. [CrossRef] [PubMed]

2. Hayward, J.N.; Baker, M.A. Role of cerebral arterial blood in the regulation of brain temperature in the monkey. Am. J. Physiol. 1968, 215, 389-403. [CrossRef] [PubMed]

3. Sukstanskii, A.L.; Yablonskiy, D.A. Theoretical model of temperature regulation in the brain during changes in functional activity. Proc. Natl. Acad. Sci. USA 2006, 103, 12144-12149. [CrossRef] [PubMed]

4. Falk, D. Brain evolution in Homo: The "radiator" theory. Behav. Brain Sci. 1990, 13, 333-344. [CrossRef]

5. Nybo, L.; Secher, N.H.; Nielsen, B. Inadequate heat release from the human brain during prolonged exercise with hyperthermia. J. Physiol. 2002, 545, 697-704. [CrossRef]

6. Ishigaki, D.; Ogasawara, K.; Yoshioka, Y.; Chida, K.; Sasaki, M.; Fujiwara, S.; Aso, K.; Kobayashi, M.; Yoshida, K.; Terasaki, K.; et al. Brain temperature measured using proton MR spectroscopy detects cerebral hemodynamic impairment in patients with unilateral chronic major cerebral artery steno-occlusive disease: Comparison with positron emission tomography. Stroke 2009, 40, 3012-3016. [CrossRef]

7. Axelrod, Y.K.; Diringer, M.N. Temperature management in acute neurologic disorders. Neurol. Clin. 2008, 26, 585-603. [CrossRef]

8. Wang, C.X.; Stroink, A.; Casto, J.M.; Kattner, K. Hyperthermia exacerbates ischaemic brain injury. Int. J. Stroke 2009, 4, 274-284. [CrossRef]

9. Murakami, T.; Ogasawara, K.; Yoshioka, Y.; Ishigaki, D.; Sasaki, M.; Kudo, K.; Aso, K.; Nishimoto, H.; Kobayashi, M.; Yoshida, K.; et al. Brain temperature measured by using proton MR spectroscopy predicts cerebral hyperperfusion after carotid endarterectomy. Radiology 2010, 256, 924-931. [CrossRef] 
10. Nakano, T.; Nishigami, C.; Irie, K.; Shigemori, Y.; Sano, K.; Yamashita, Y.; Myose, T.; Tominaga, K.; Matsuo, K.; Nakamura, Y.; et al. Goreisan prevents brain edema after cerebral ischemic stroke by inhibiting aquaporin 4 upregulation in mice. J. Stroke Cerebrovasc. Dis. 2018, 27, 758-763. [CrossRef]

11. Doerfler, A.; Forsting, M.; Reith, W.; Staff, C.; Heiland, S.; Schabitz, W.R.; von Kummer, R.; Hacke, W.; Sartor, K. Decompressive craniectomy in a rat model of "malignant" cerebral hemispheric stroke: Experimental support for an aggressive therapeutic approach. J. Neurosurg. 1996, 85, 853-859. [CrossRef] [PubMed]

12. Schwab, S.; Steiner, T.; Aschoff, A.; Schwarz, S.; Steiner, H.H.; Jansen, O.; Hacke, W. Early hemicraniectomy in patients with complete middle cerebral artery infarction. Stroke 1998, 29, 1888-1893. [CrossRef] [PubMed]

13. Karaszewski, B.; Carpenter, T.K.; Thomas, R.G.; Armitage, P.A.; Lymer, G.K.; Marshall, I.; Dennis, M.S.; Wardlaw, J.M. Relationships between brain and body temperature, clinical and imaging outcomes after ischemic stroke. J. Cereb. Blood Flow Metab. 2013, 33, 1083-1089. [CrossRef]

14. Karaszewski, B.; Wardlaw, J.M.; Marshall, I.; Cvoro, V.; Wartolowska, K.; Haga, K.; Armitage, P.A.; Bastin, M.E.; Dennis, M.S. Early brain temperature elevation and anaerobic metabolism in human acute ischaemic stroke. Brain 2009, 132, 955-964. [CrossRef] [PubMed]

15. Vescovo, E.; Levick, A.; Childs, C.; Machin, G.; Zhao, S.; Williams, S.R. High-precision calibration of MRS thermometry using validated temperature standards: Effects of ionic strength and protein content on the calibration. NMR Biomed. 2013, 26, 213-223. [CrossRef] [PubMed]

16. Corbett, R.; Laptook, A.; Weatherall, P. Noninvasive measurements of human brain temperature using volume-localized proton magnetic resonance spectroscopy. J. Cereb. Blood Flow Metab. 1997, 17, 363-369. [CrossRef]

17. Dehkharghani, S.; Fleischer, C.C.; Qiu, D.; Yepes, M.; Tong, F. Cerebral temperature dysregulation: MR thermographic monitoring in a nonhuman primate study of acute ischemic stroke. AJNR Am. J. Neuroradiol. 2017, 38, 712-720. [CrossRef]

18. Corbett, R.J.; Purdy, P.D.; Laptook, A.R.; Chaney, C.; Garcia, D. Noninvasive measurement of brain temperature after stroke. AJNR Am. J. Neuroradiol. 1999, 20, 1851-1857.

19. Karaszewski, B.; Wardlaw, J.M.; Marshall, I.; Cvoro, V.; Wartolowska, K.; Haga, K.; Armitage, P.A.; Bastin, M.E.; Dennis, M.S. Measurement of brain temperature with magnetic resonance spectroscopy in acute ischemic stroke. Ann. Neurol. 2006, 60, 438-446. [CrossRef]

20. Weis, J.; Covaciu, L.; Rubertsson, S.; Allers, M.; Lunderquist, A.; Ortiz-Nieto, F.; Ahlström, H. Phase-difference and spectroscopic imaging for monitoring of human brain temperature during cooling. Magn. Reson. Imaging 2012, 30, 1505-1511. [CrossRef]

21. Yamada, K.; Sakai, K.; Akazawa, K.; Yuen, S.; Sugimoto, N.; Sasajima, H.; Mineura, K.; Nishimura, T. Moyamoya patients exhibit higher brain temperatures than normal controls. Neuroreport 2010, 21, 851-855. [CrossRef] [PubMed]

22. Kuroda, K. Non-invasive MR thermography using the water proton chemical shift. Int. J. Hyperth. 2005, 21, 547-560. [CrossRef] [PubMed]

23. Weis, J.; Covaciu, L.; Rubertsson, S.; Allers, M.; Lunderquist, A.; Ahlström, H. Noninvasive monitoring of brain temperature during mild hypothermia. Magn. Reson. Imaging 2009, 27, 923-932. [CrossRef] [PubMed]

24. Covaciu, L.; Rubertsson, S.; Ortiz-Nieto, F.; Ahlström, H.; Weis, J. Human brain MR spectroscopy thermometry using metabolite aqueous-solution calibrations. J. Magn. Reson. Imaging 2010, 31, 807-814. [CrossRef] [PubMed]

25. Cady, E.B.; Penrice, J.; Robertson, N.J. Improved reproducibility of MRS regional brain thermometry by 'amplitude-weighted combination'. NMR Biomed. 2011, 24, 865-872. [CrossRef] [PubMed]

26. Verius, M.; Frank, F.; Gizewski, E.; Broessner, G. Magnetic resonance spectroscopy thermometry at 3 Tesla: Importance of calibration measurements. Ther. Hypoth. Temp. Manag. 2019, 9, 146-155. [CrossRef]

27. Zhu, M.; Bashir, A.; Ackerman, J.J.; Yablonskiy, D.A. Improved calibration technique for in vivo proton MRS thermometry for brain temperature measurement. Magn. Reson. Med. 2008, 60, 536-541. [CrossRef]

28. Thrippleton, M.J.; Parikh, J.; Harris, B.A.; Hammer, S.J.; Semple, S.I.; Andrews, P.J.; Wardlaw, J.M.; Marshall, I. Reliability of MRSI brain temperature mapping at 1.5 and 3 T. NMR Biomed. 2014, 27, 183-190. [CrossRef]

29. Inoue, T.; Shimizu, H.; Fujikura, M.; Saito, A.; Yoshioka, Y.; Matsuda, T.; Tominaga, T. Noninvasive measurement of human brain temperature adjacent to arteriovenous malformation using 3.0T magnetic resonance spectroscopy. Clin. Neurol. Neurosurg. 2013, 115, 445-449. [CrossRef]

30. Derdeyn, C.P.; Videen, T.O.; Fritsch, S.M.; Carpenter, D.A.; Grubb, R.L., Jr.; Powers, W.J. Compensatory mechanisms for chronic cerebral hypoperfusion in patients with carotid occlusion. Stroke 1999, 30, 1019-1024. [CrossRef]

31. Schwab, S.; Spranger, M.; Aschoff, A.; Steiner, T.; Hacke, W. Brain temperature monitoring and modulation in patients with severe MCA infarction. Neurology 1997, 48, 762-767. [CrossRef] [PubMed]

32. Ginsberg, M.D.; Sternau, L.L.; Globus, M.Y.; Dietrich, W.D.; Busto, R. Therapeutic modulation of brain temperature: Relevance to ischemic brain injury. Cerebrovasc. Brain Metab. Rev. 1992, 4, 189-225. [PubMed] 